\title{
Expresiones geopolíticas sobre el desarrollo de las fronteras del Tarapacá Histórico (1974-2018): ¿movilidades fronterizas como fuente de amenaza?*
}

\author{
Geopolitical expressions on the development of the borders of the Historic \\ Tarapacá (1974-2018): Border mobility as a source of threat?
}

\author{
Cristian Ovando Santana** \\ Romina Ramos Rodríguez ${ }^{* * *}$
}

\begin{abstract}
Resumen: La zona del extremo norte de Chile es poseedora de una posición geográfica que la obliga a pensar su desarrollo de cara a los vecinos con que comparte frontera, previendo, además, una excesiva distancia del centro político y padeciendo una cultura centralista centenaria. Esta ubicación espacial ha resultado problemática para diversas autoridades centrales, llevando a sobredimensionar el factor geopolítico en el diseño de sus estrategias de desarrollo. Este panorama se expresa con mayor nitidez a partir de la dictadura militar, aunque persistiendo con matices desde la vuelta a la democracia. Con todo, este trabajo, desde una perspectiva crítica, busca identificar la presencia recurrente de una narrativa geopolítica clásica en el seno de algunas iniciativas de desarrollo del Tarapacá Histórico. Expresadas en una serie de iniciativas públicas desde 1974 hasta la actualidad, y centradas en controlar los flujos presentes en periferia. Con todo, conjeturamos que se subestiman las posibilidades de la integración fronteriza de la región, toda vez que se ha tendido a securitizar las fronteras, en el marco de proyectos políticos neoliberales.
\end{abstract}

Palabras clave: Geopolítica clásica y crítica; Tarapacá, estrategias de desarrollo; movilidad fronteriza

Abstract: The northern part of Chile has a geographical position that forces it to think about its development in the face of the neighbors with which it shares a

* Resultado de Proyecto FONDECYT de Iniciación 11170816

** Chileno, autor principal. Doctor en Relaciones Internacionales, Universidad del País Vasco. Académico del Instituto de Estudios Internacionales INTE de la Universidad Arturo Prat. Contacto: covando@unap.cl Dirección postal: Avenida Arturo Prat 2120, Casilla 121, Iquique, Chile

*** Chilena, autora secundaria. Doctora en Modelos y Áreas de investigación en Ciencias Sociales, Universidad del País Vasco. Académica de la Facultad de Ciencias Jurídicas y Políticas de la Universidad Arturo Prat e investigadora del Núcleo de Estudios Criminológicos de Frontera, Iquique, Chile. Contacto: romramos@unap.cl. Dirección postal: Avenida Arturo Prat 2120, Casilla 121, Iquique, Chile 
border, also providing for an excessive distance from the political center and suffering from a centennial centralist culture. This spatial location has proved problematic for various central authorities, leading to oversizing the geopolitical factor in the design of their development strategies. This panorama is expressed more clearly from the military dictatorship, although persisting with nuances since the return to democracy. However, this work, from a critical perspective, seeks to identify the recurring presence of a classic geopolitical narrative within some development initiatives in the Tarapacá region. This is expressed in a series of public initiatives from 1974 to the present, focused on controlling the flows present in the periphery and underestimating the possibilities of border integration in the region, since it has tended to secure the borders, within the framework of neoliberal political projects.

Keywords: Classic and critical geopolitics; Tarapacá, development strategies; border mobility

Recibido: 24 julio 2019 Aceptado: 4 septiembre 2019

\section{Introducción}

La zona Norte de Chile surge como un espacio conquistado militarmente, por tanto, ha padecido los efectos de guerras y asonadas fronterizas, la presencia de doctrinas militares con aprensiones hacia las zonas contiguas (Von Chrismar, 1993), junto con el diseño y puesta en marcha de una serie políticas públicas para fortalecer la presencia del Estado en el confín (Ghisolfo, 1989; Correa y Salas, 2015).

Como corolario, por décadas las estrategias de desarrollo regional implementadas en este espacio, han estado sometidas a fricciones, conflictos y desequilibrios con el Estado, consecuencia de su ubicación geográfica próxima con Perú y Bolivia; la lejanía de la capital y la presencia de una marcada tradición centralista, que ha contribuido, en ocasiones, a obviar y frustrar sentidas demandas regionales (Ríos 1992; Ovando y González, 2018). En este contexto, el centralismo ha sido influyente en las propuestas de desarrollo regional nortino, expresándose, dentro de otras dimensiones, a través de medidas de inspiración geopolítica ${ }^{1}$, que han cargado de sentido y significado a sus iniciativas y discursos (Narváez y Quiroz, 2014; Santana, 2013).

\footnotetext{
${ }^{1}$ Aunque el término geopolítica desde a mediados de la década de 1970 coloquialmente se utiliza para referirse a toda rivalidad global en la política internacional. Esta acepción se le atribuye a cómo la prensa recogió las confrontaciones por las esferas, espaciales, de influencia en la Guerra Fría. Particularmente a partir de las ideas expresadas por el secretario de Estado Henry Kissinger, se popularizó esta acepción del término geopolítica en los medios (Hepple, 1986).
} 
La geopolítica clásica chilena, de raigambre alemana (Cabrera, 2018), adhería a una noción darwinista-organicista (García Huidobro, 1978; Child, 1981; Pitmann, 1981; Bravo, 1982; Canessa, 1982; Ghisolfo, 1989; Von Chrismar, 1993), vinculada a los imperativos que impondría la lucha por su supervivencia en un entorno vecinal conflictivo (Tapia, 1980). El Estado como organismo vivo -por analogía- estaría sometido a ciertas leyes hipotéticas de uso generalizado (Von Chrismar, 1993, 2007) y sujeto a influencias naturales, que derivarían en su impulso de expansión. Desde estas premisas, su crecimiento no dependería de su voluntad, sino que sería natural a su condición. Este proceso orgánico, inherente a su existencia misma, a su salud y evolución, podría ser encauzado debidamente, para que el crecimiento sea normal y armónico (Von Chrismar, 2000).

La geopolítica clásica, por tanto, puso énfasis en las variables geográficas como dimensión fundamental para orientar la conducción del Estado o guía del estadista (Pitmann, 1981; García Huidobro, 1978), además de considerar los factores históricos que evidenciaban la persistencia de conflictos fronterizos, a partir de la ponderación "del valor geopolítico de las tierras en litigio con los Estados vecinos" (Santis, 1998: 138-139). Desde el ámbito académico-militar chileno, la geopolítica se definía como "el estudio de la influencia de los factores geográficos en la vida y evolución de los Estados para deducir conclusiones de carácter político, que permitan planificar y desarrollar el poder nacional" (García Huidobro, 1978:17). Ésta, con cierta vigencia hasta hoy, prioriza su conocimiento con el poder establecido y con la dimensión territorial de este último (Nogue y Rufí, 2001), partiendo de que la prioridad de toda política pública era el problema del espacio y su dominio, particularmente el espacio periférico propio de las regiones extremas.

Esta situación lleva a la sobredimensión de los factores geográficos e históricos, éstos últimos con referencia al territorio y a la conducción del Estado, como la topografía, clima, demografía, localización, tamaño, recursos naturales, cultura, etc., (Detlef y Wehner, 2016). Es decir, lo que predomina en la concepción del estratega, es la tendencia a concebir el control territorial como la dimensión clave de su quehacer. Sobre todo, en las regiones extremas donde este control se puede ver cuestionado por una serie de factores que amenazan su seguridad. Dentro de ellos, destacamos la presencia de enclaves étnicos extranjeros y su presión demográfica hacia el confín, la distancia del territorio con el núcleo vital2 $^{2}$ la presencia de recursos valiosos objeto de disputas, la existencia de zonas "vacías o grises", entre otros factores.

Con el fin de la Guerra fría y la democratización del continente, no obstante, en Sudamérica el pensamiento geopolítico se renueva, pasando a hacer una preocupación universitaria, que

\footnotetext{
2 Núcleo vital o espacio vital es un concepto de uso extendido por la geopolítica clásica chilena, de inspiración ratzeliana (Santis, 1998), se centra en la estrecha relación entre espacio y población, afirmando que la sobrevivencia de todo Estado se garantiza cuando dispone del suficiente espacio para atender a sus necesidades.
} 
se distancia del determinismo y fatalismo geográfico, y "abriendo paso a las nuevas corrientes -epistemológicamente más cercanas al interpretativismo- como la geopolítica crítica y sus diferentes enfoques. (Cabrera, 2018)

Para una de las variantes de la geopolítica crítica, que sospecha de los principios geopolíticos clásicos, los espacios de la política internacional y fronteriza, producidos desde representaciones y prácticas, "se hacen visibles en todo tipo de planes estratégicos e imaginaciones relacionadas" (Moisio 2015: 224-25). Estos imaginarios espaciales proporcionan marcos cognitivos, dan sentido a los eventos y legitiman decisiones políticas particulares, desentrañando las valoraciones que subyacen a sus iniciativas, tendencias y narrativas. Por ejemplo, es el caso del Plan Maestro Parinacota, diseñado por la Dirección de Desarrollo Estratégico del MINREL (Ruiz, 2018), el cual tiene una mirada que pone el acento en la idea que persiste una escasa presencia histórica del Estado en la frontera y los problemas que acarrea. Este ejemplo Lo desarrollaremos más adelante.

Con todo, la geopolítica crítica trata sobre la organización política del espacio y sobre cómo se concibe, representa y utiliza esto en la discusión política (Dalby, 2009). Ergo, desde estas perspectivas críticas ${ }^{3}$, esta sobredimensión de los factores geográficos (o fatalismo geográfico), se expresa en discursos hegemónicos que buscan representar a las regiones periféricas o espacios fronterizos como problemáticos, inertes y exóticos (Serje, 2017) y, en particular de nuestro caso de estudio, representados y cartografiados ${ }^{4}$ (Porcaro, 2019) como espacios vacíos e inhóspitos; caóticos o próximos a la ficción de la anarquía internacional (Weldes, 2009); desprovistos de sociabilidad relevante; zonas grises, distantes del núcleo vital del Estado y próximos a vecinos revisionistas y productores de droga (Von Chrimar, 1997). En concreto, ¿Persiste la geopolítica clásica como guía de políticas públicas hacia las fronteras pese a su anacronismo?

Como hemos visto, para el caso chileno, todavía persisten los denominados riesgos geopolíticos asociados a las fronteras interiores o espacios vacíos dentro del sistema geográfico. Estos coinciden con las regiones extremas del norte y sur del país, cuya densidad demográfica y política poblacional constituyen uno de los mayores desafíos del país, "pues todavía los problemas del sistema político son analizados desde una óptica geo clásica" (Carvajal 2007:46). Pero, ¿Por qué persiste este discurso clásico, susceptible de ser analizado

\footnotetext{
3 La geopolítica critica, dentro de sus aristas, genera explicaciones en torno a los distintos discursos territoriales y sus representaciones (Cairo,1993; Claval, 1995; O`tuathail y Dalby, 1998), para así poder conocer y ponderar los elementos subyacentes que se encuentran, especialmente, en el discurso oficial sobre un espacio territorial (Agnew, 2013).

4 Los nuevos enfoques cuestionan, por un lado, la concepción de los mapas como neutros, ahistóricos y miméticos. La relación entre el mapa y el referente empírico nunca es transparente e inmediata, sino que configura un objeto diferente del que dice mostrar (Ibid.). Los mapas parten de un conjunto de supuestos culturales y epistemológicos que se expresan a través de las estrategias de selección, composición, encuadre y representación gráfica (Cosgrove, 2008; Porcaro, 2019).
} 
desde orientaciones críticas, pese a su superación por miradas multidimensionales para entender el desarrollo de las zonas extremas?

Dentro de las razones que se pueden esgrimir para constatar la resistencia del geopolítica clásica chilena para abrirse a nuevos debates, encontramos que persiste un principio que hace que los territorios que cubren Tarapacá Histórico ${ }^{5}$, están cargados de significación geográfica (Cairo y Lois 2014), dada las anexiones territoriales que obtuvo Chile como consecuencia de la Guerra Del Pacifico (Santis, 1998). Por otro lado, en algunas coyunturas históricas y actuales - por ejemplo, en el marco del Fallo de La Haya (Ovando, 2019)-, las disputas diplomáticas en torno a esta frontera siguen constituyendo una ocasión para la reafirmación de la "solidez" de los Estados involucrados (Cairo y Lois 2014). También destacamos la escaza proyección de la política exterior chilena hacia marcos geográficos de referencia distintos al nacional, debido a la negativa de sucesivos gobiernos a ingresar como miembros plenos en mecanismos de integración complejos como MERCOSUR Y CAN6 (Nolte yWhener ,2010). Esta tendencia ha llevado a sobredimensionar el territorio nacional y a definir una noción tradicional de soberanía (Guerrero, 2014) Además la falta de una adecuada descentralización política (Valenzuela, 2015), ha llevado a subestimar las respuestas locales ante el problema de las fronteras interiores.

Inicialmente, delimitamos el problema de este trabajo en términos de discurso/concepción 'oficial' del Estado chileno hacia la frontera norte y su análisis crítico. Para ello, también, desde la geopolítica critica, intentaremos a desentrañar (o 'deconstruir', en términos de Ó Tuathail) esta frontera como problema amplio (también informal y transnacional), y no solo como representación subjetiva oficial. Exploraremos, en términos más amplios, en qué medida las dinámicas globales del Tarapacá Histórico, como conjunto, afectan realmente a la concepción/definición de las políticas públicas por parte del Estado chileno en aquella región (diplomáticas, militares, y sociales-informales). Para ello, profundizaremos en los cambios contextuales ocurridos en el área en cuestión que, asociados a la Globalización (flujos de mercancías y personas, movilidades interdependencias, pueblos ancestrales, etc.) han incidido notoriamente en despliegue del el propio Estado chileno, modificando sus posiciones a lo largo de los últimos años.

\footnotetext{
5 A efectos de este estudio, entendemos “Tarapacá Histórico", el territorio que abarca las regiones de Arica y Parinacota y Tarapacá, ubicadas en el extremo norte de Chile. Estas regiones se dividieron administrativamente en el año 2007. No obstante, su historia compartida nos permite considerar sus fenómenos geopolíticos de manera conjunta. De este modo, entendemos el espacio como construcción social donde se crea la vida cotidiana que le otorga sentido y significado a los espacios (Lassault, 2015:45). Esta posición viene a desnaturalizar el concepto de espacio geográfico, pues asumimos, que éste no es un ente natural sino un subproducto social del modo de producción y que su comprensión sólo es posible a partir de una geohistoria que implique el conocimiento de los procesos involucrado y las tensiones a escala global y local (Harvey, 2001).

6 Por ejemplo, la Comunidad Andina promueve la instancia para el desarrollo de regiones fronteriza denominado ZIF, Zonas De Integración Fronteriza.
} 
Con todo, el objetivo de este artículo es identificar la presencia recurrente de una narrativa geopolítica clásica en el seno de una serie de iniciativas de desarrollo en el espacio que concebimos, a efectos de este estudio, como el Tarapacá Histórico. Las que si bien con matices, que desarrollaremos a lo largo del trabajo, ha marcado el derrotero de estos espacios desde 1974. Para ello, la propuesta metodológica es cualitativa, basándose en la revisión crítica del contexto histórico, mediante el análisis descriptivo de los contenidos desde fuentes de información publicadas en prensa local, nacional y análisis de discurso obtenidos de los documentos oficiales del Gobierno de Chile; Ministerio de Relaciones Exteriores; Ministerio del Interior y Seguridad Pública; Gobierno Regional de Tarapacá, Intendencia Regional de Tarapacá, Oficina de Planificación, entre otros. Para lo anterior, se apuesta por un análisis genealógico, en el ámbito del desarrollo regional del Tarapacá histórico. Es decir, consideramos un método que consiste en construir la historia del presente en base a las identidades y los intereses enfrentados e intentar mirar los sucesos, analizando las condiciones materiales y simbólicas que soportan los acontecimientos (Santillana, 2010). Es por ello, que esta propuesta permite rastrear la persistencia de la noción geopolítica, retrocediendo a un tiempo anterior para conocer el poder de nuevas influencias que afectan a las personas e instituciones en el presente (Vidal, 2003).

El artículo se organiza de la siguiente manera: en primer lugar, indagamos en algunas acciones y discursos estatales y regionales que incorporan el componente geopolítico desde 1974 hasta 1990, mediante el abordaje de expresiones de la acción gubernamental en clave seguridad/ desarrollo y su crítica teórica. A continuación, indagamos en la agenda pública que da cuenta de la persistencia del componente geopolítico pos dictadura, esta vez incorporando discusiones teóricas en torno a nuevas amenazas y sus aplicaciones en planes específicos, junto con ello, indagamos en otras formas de poder que compiten y/o conviven con el Estado chileno en Tarapacá. Finalmente, se presentarán las principales conclusiones.

\section{Tarapacá histórico: algunos antecedentes previos.}

En cuanto a la posición geográfica de Tarapacá histórico y los recursos productivos que ostenta, determinantes en el diseño de sus estrategias, ha sido importante el desarrollo pesquero, portuario y minero, particularmente, la extracción del guano, salitre y en la actualidad la gran minería del cobre ${ }^{7}$ (González, 2016). Dentro de sus demandas, se identifica, para el caso de Iquique, su vocación integracionista que tiene su origen en demandas históricas de integración entre Oruro e Iquique (Harms, 1930; Gonzalez, 2011). Arica, en cambio, tiene una vocación histórica geo militarista por constituirse en región conquistada por mayor tiempo (hasta 1929), lo que influyó en el imaginario local bajo consignas como "hacer patria". También fue y es clave el transporte marítimo-vial y el

${ }^{7}$ Cabe mencionar que la mayoría de los yacimientos mineros apostados en el Norte Grande, se encuentran ubicados en la franja fronteriza y que la exportación de minerales se hace por los puertos chilenos del Pacífico. 
comercio vía rutas internacionales que conectan al norte de Chile con el Asia Pacifico y el centro este de Sudamérica (Tapia y Chacón, 2016), dada una posición geográfica privilegiada, que le permite establecer puentes con el mercado del Asia Pacifico vía corredores bioceánicos $^{8}$ (Tapia, 2004). Además de este dinamismo ligado a la conectividad internacional, en el caso de la provincia de Iquique, desde el año 1975 se crea la Zona Franca (en adelante, ZOFRI) como principal instrumento de desarrollo y reactivación de actividades productivas y servicios regionales (Icarte et al., 2018). Su objetivo fue impulsar el desarrollo de la primera región que en ese momento atravesaba una crisis económica ocasionada por la inestabilidad de la industria pesquera y la imposibilidad de reflotar el salitre como fuente de divisas (González, 1992). No obstante, estas nuevas aristas en el ámbito económico, convivieron con una geopolítica tradicional que se ha mantenido en el tiempo como ejes de discusión y construcción de una agenda pública regional. Estos elementos implicaron darle un valor estratégico a esta zona, considerándola dentro de las prioridades de agendas geopolíticas, en la medida que ha sido una constante el desequilibrio notorio entre potencial económico y baja densidad poblacional, constituyéndose una amenaza potencial a la seguridad y al desarrollo (Guisolfo, 1989). Ejemplo de lo anterior, es que desde sus inicios la distribución de utilidades de ZOFRI fue pensada para financiar el desarrollo de las comunas rurales de la Provincia del Tamarugal, apuntado, dentro de otras cosas, a su poblamiento. Así lo señala un documento donde indica que ZOFRI surgió como una respuesta del Estado ante la necesidad demográfica y geopolítica de contar con un potente polo de desarrollo social y económico en el extremo norte de Chile (Decreto Ley $\mathrm{N}^{\circ} 1.055$, Biblioteca del Congreso Nacional).

También es clave destacar una tendencia a la securitización ${ }^{9}$ del espacio fronterizo el norte de Chile, lo que en las últimas décadas ha reconfigurado la frontera en su utilidad (Ramos, 2018). Esta tendencia, materializada desde la década de 1990, se enmarca, por un lado, en la capacidad potencial que tienen los espacios fronterizos para responder a la movilización de capital, como consecuencia de la apertura económica que mantiene Chile a nivel mundial ${ }^{10}$. Por otro lado, estas dinámicas llaman a robustecer el control fronterizo de estos territorios funcionales a esta dinámica económica, por ser considerados claves para el éxito de la estrategia comercial consolidada. Como han puntualizado Dilla y Álvarez (2019), la habilitación demográfica, productiva e institucional de las zonas (trans) fronterizas ha derivado de los apremios geopolíticos que no se compadecían de las múltiples relaciones informales consuetudinarias distantes de la política formal.

8Esto abre una nueva arista geopolítica en torno a la competencia portuaria con el sur del Perú y el control del acceso al Pacífico (Mercado, 1996).

${ }_{9}^{9}$ Es decir, el ingreso de un tema de interés público a la agenda de seguridad, que tradicionalmente es visto desde otras perspectivas, por ejemplo, como un tema propio de la agenda de desarrollo

$10 \mathrm{Al}$ año 2019, Chile tiene 28 acuerdos comerciales que involucran 64 países. Con estos tratados se logra acceder a un mercado preferencial que alcanza el $63 \%$ de la población mundial. Más información, En https://www.subrei.gob.cl/modulo-de-acuerdos-comerciales/. 
Dentro de la dimensión política de los problemas que aquejan al extremo norte, como hemos esbozado someramente, desde mediados del siglo XX podemos identificar su difícil y escaso poblamiento (Guisolfo,1989); las dificultades para administrar una endeble institucionalidad regional (Podestá, 2004); un exacerbado centralismo; las limitaciones institucionales que postergan el desarrollo de la región y fomentan su descontento (Soza Amigo y Correa, 2014); su condición geográfica desértica y altiplánica; la percepción chilena en torno a la recuperación de Tarapacá y Arica por parte de Perú a partir de un supuesto revanchismo (Von Chrismar 1993; Silva et al., 2018); la preeminencia de extensas áreas rurales denominadas 'fronteras interiores', o zonas escasamente pobladas, con bajos índices de desarrollo humano de su población y apartadas del núcleo vital del Estado (Sanz, 2014). Territorios que además coinciden con la proliferación de actividades ilícitas ligadas al contrabando y narcotráfico, muchas de ellas abordadas por nuevas políticas de control fronterizo que consideran estos espacios como zonas vulnerables dada la cercanía con el límite internacional (García Pinzón, 2015)

\section{La mirada de la dictadura militar sobre el desarrollo de Tarapacá Histórico y su frontera (1973-1990)}

\subsection{Fundamentos geopolíticos del proceso regionalizador}

Con la ruptura del orden institucional vigente, encabezado por la Unidad Popular y la arremetida de la dictadura militar, a partir de 1974 se impone sin debate público alguno un afán refundacional dentro de las iniciativas estatales (Olguín, 2018). Particularmente las referidas al desarrollo regional donde la geopolítica y la geografía, su ciencia auxiliar, cobran una inusitada relevancia (Quiroz y Narváez 2014:43-50).

Aunque cabe destacar que el pensamiento geopolítico chileno se origina desde la década de 1940 a partir de los aportes del general Cañas Montalvo (Santis, 1998). Este inculcó la necesidad de sostener herramientas geográficas para la acción política, las que visionariamente deberían fijar los objetivos políticos a largo plazo de la nación chilena dada su configuración geográfica compleja (Santis, 1998). Este destino manifiesto planteaba que los estadistas debían sortear el determinismo geográfico, en su visión de proyecto país, como un imperativo irrenunciable.

Como guía del estadista (Pitmann, 1981), se profundizó en la supuesta cientificidad y criterios técnicos de los argumentos geopolíticos, en tanto mecanismo de legitimación y 
autoridad de la dictadura, para abordar el proceso de regionalización ${ }^{11}$ y en donde las fronteras asumen un rol clave, como argumentaremos a continuación.

En este marco se crea la Comisión Nacional de Regionalización y Administración, CONARA que, inicialmente, se opuso a las reformas neoliberales que orientaron el quehacer de la dictadura (Olguín, 2019). Lo anterior, dado que los principios geopolíticos que inspiraban las estrategias de desarrollo de las regiones extremas, se superponían a los criterios neoliberales que, poco a poco, comienzan a posicionarse, especialmente en el debate sobre los criterios de inversión pública sostenida para poblar los extremos ${ }^{12}$.

En concreto, a través de la conducción de sus técnicos inspirados por la geopolítica, esta agencia sostuvo que el desarrollo y la seguridad son los pilares del poder nacional (Iturriaga, 1983), promoviéndose la regionalización y sus énfasis en los territorios periféricos. En sus diagnósticos y objetivos nacionales, en torno a crear polos de desarrollo en regiones fronterizas históricamente despobladas y con serios problemas de habitabilidad, el criterio de la seguridad fue clave, como indica resumidamente documento de la CONARA (1976):

Es necesario que exista un equilibrio fronterizo bien definido y el país esté sólidamente cohesionado en su interior (...). Ello plantea como tarea ineludible una vinculación entre la integración nacional y los objetivos de la seguridad del país. No favorecen lo anterior, si el país presenta numerosos espacios vacíos dentro del territorio nacional o áreas de bajo desarrollo (1976:103).

Así también, lo destaca la Estrategia regional de desarrollo de la Provincia de Tarapacá de 1985, publicada por la Comisión de Seguridad Nacional y Geopolítica:

El problema que presenta nuestro alargado territorio (...) resalta la importancia de regiones extremas que no deben representar en absoluto ningún tipo de debilidad, situación que refleja el permanente interés que debe tener el Estado nación hacia Tarapacá.

Esta estrategia también expresaba que la vinculación entre seguridad nacional y desarrollo regional, la encontramos en que la regionalización tendería al desarrollo económico en

11 La nueva división político administrativa dirigida por la CONARA, denominada regionalización, buscaba integrar territorialmente a las nuevas regiones, maximizar la disposición de sus recursos naturales y constituir una equilibrada distribución geográfica del país (Narváez y Quiroz, 2014).

12 Estos principios originalmente digitados desde ODEPLAN antes del quiebre a la democracia, tenían una raigambre desarrollista que se fundamentaba en el rol del Estado para llevar el desarrollo a todo el territorio nacional a través de soluciones técnicas. Estos fueron mutando desde la CONARA, sustentando desde el binomio seguridad- desarrollo, el combate frente a la extrema pobreza; el freno a la migración campo-ciudad; la urgencia de polos de desarrollo regional y la despolitización social anclada en una nueva forma de hacer política (Valdivia y Donoso, 2012). 
armonía con la solución de "problemas sociales" presentes en todo el territorio nacional. Cuestión que buscaba la erradicación de la pobreza y su asociación con la Unidad Popular (Narváez y Quiroz, 2014) y, particularmente en las zonas fronterizas, a la presencia de comunidades foráneas y pobreza rural (Santana, 2013). Por ejemplo, para el Tarapacá Histórico, se intentaba prevenir los riesgos para el país derivados de su localización geográfica. Esto es su "condición de región anexada" al territorio nacional y la presencia de una constante movilidad de comunidades aymaras y extranjeras (peruanas y bolivianas), que deberían estar sujetas a control estatal (Santana, 2013). Asimismo, en el caso de Arica, se buscaba prevenir los riesgos derivados de su histórico movimiento regionalista (Ríos, 1992), a propósito de la capacidad de movilización de la sociedad local desde la década de 1930, por un proyecto político regional de reconocimiento territorial.

En efecto, se le denominaba "frente interno" a cualquier asociación política disidente con el proyecto restaurador como principal problema social (Estrategia de Desarrollo Regional, 1985). Este era el caso de muchas comunidades aymaras que habitaban la frontera tarapaqueña sumidas en la pobreza. Argumento que retomaremos más adelante.

\subsection{Alcances geopolíticos en algunas estrategias: despoblamiento y movilidad transfronteriza como amenazas}

En este contexto, se crean planes de inspiración geopolítica más expresivos que en gobiernos anteriores 13 , en los que la seguridad ante posibles amenazas vecinales eran un elemento clave para las estragadas de desarrollo, pues recordemos que la geopolítica se consideraba la guía del estadista para las dictaduras militares de la época (Pitmann, 1981). En Arica, por ejemplo, se pone en marcha la Comisión de Desarrollo del Interior como parte del Plan Andino ${ }^{14}$. Aquí se continuó la inversión en infraestructura y en programas asistenciales, pero ahora de la mano de una visión geopolítica que mostraba preocupación por el espacio andino en su condición de espacio "limítrofe", con dos países considerados potencialmente hostiles. Así, además de una serie de medidas asistencialistas para reactivar la economía deprimida15, se establecieron estrategias de integración nacional de la periferia que

13 En 1953 se crea el Puerto Libre de Arica que de forma inmediata activa la economía ariqueña, proyectándola al resto del país y sobre Perú y Bolivia (Ruz et al., 2015). El impacto de este instrumento fue notorio y, según Ríos (1992:17 y ss.), la población económicamente activa creció de 8.954 trabajadores en 1952 a 22.731, en 1968; entre 1962 y 1968 la producción de la industria electrónica aumentó más de 18 veces; en 1966, las actividades productivas tuvieron un movimiento operacional cercano a los 36 millones de dólares; y entre 1964 y 1968 las exportaciones pesqueras casi duplican su monto en dólares.

14 El Plan Andino para la zona de Arica, gestionó, en coordinación con otras instituciones públicas, recursos importantes para obras de infraestructura y equipamiento urbano (agua potable, alcantarillado, baños públicos, sedes sociales, luz eléctrica), de conectividad (redes viales), de mejoramiento de condiciones productivas y tecnológicas (Galdames y Ruz, 2010).

15 Cabe señalar, que los ariqueños guardan poca estima por la gestión de la dictadura militar desde 1973, cuando Arica fue penalizada con el desmantelamiento económico y el conflicto geopolítico (Dilla, 2018). 
brindaban a la comunidad una estructura social más definida, funcional y organizada y una educación más de acuerdo con las exigencias del medio, tensionado por la presión demográfica que imponían por comunidades aymaras peruanas y bolivianas, y ante una escasa población chilena ${ }^{16}$. Lo anterior, con la finalidad de aumentar su productividad y, así, integrarlos a la economía regional, junto con dotarles de los medios de comunicación adecuados para permitirles una integración progresiva al medio regional y nacional (Quiroz et al. 2011:162 y ss.).

Siguiendo a Quiroz y Narváez, (2014: 33 y ss.), dentro de las bases de este proyecto restaurador, desde un saber geográfico propio del "experto" profesional o planificador, se profundizó en la planificación del desarrollo con efectos relevantes en las franjas fronterizas, "negando implícitamente la capacidad creativa de las prácticas geográficas, en el sentido de imaginar una nueva espacialidad social o instituir una geografía compenetrada con las producciones populares o socialmente activas" (Quiroz y Narváez, 2014: 33-34)

En el caso de la franja fronteriza de Tarapacá esta tendencia terminó naturalizando un espacio nacional (Núñez, 2012), obviando todo intento de imaginar espacialidades locales en donde el componente transfronterizo fuese clave para el desarrollo (Ovando y Ramos, 2016), junto prescindir de la presencia de actores locales, que valorasen la diversidad de formas de habitar los territorios del país (Amigo, 2017), sobre todos en regiones de frontera como Tarapacá.

Para la época, en cambio, se trataba de estrategias de desarrollo de inspiración geopolítica, fundada en una geografía de convenciones científicas y modernas:

Desde la composición geológica del suelo, pasando por la hidráulica de ríos y fronteras, hasta la superposición de imágenes satelitales y la identidad de las expresiones regionales. Pero, imperceptiblemente, también se trataba de una geografía separada de las prácticas sociales, dividida o distanciada del saber geográfico del cuerpo social, anclado en las significaciones vividas y cotidianas (Quiroz y Narváez, 2014: 44).

Del mismo modo, la geopolítica clásica dotaba de contenido a las estrategias regionales a través de la definición y aplicación de las leyes de Ratzel17 (Von Chrismar; 2000; Santis, 1998),

16En efecto, en la región de Tarapacá en la década de 1980 el curriculum educativo diseñado por la dictadura militar considera la educación fronteriza, la cual expresamente tenía por objetivo inculcar los valores y tradiciones patrias a los habitantes de la franja fronteriza, junto con integrarlos de acuerdo a los fines y objetivos definidos por el Supremo Gobierno (Van Kessel, 1990, p. 12-14)

17 Se trata de leyes de aplicación general. Ésta establecía la ley de áreas valiosas y la ley de la influencia expansiva y atractiva de los minerales. La primera ponía énfasis en las condiciones geográficas óptimas para consolidar un frente portuario en Tarapacá y la segunda en conocer y explotar al máximo potencialidades de las riquezas mineras con el debido resguardo que implica que éstas son apetecidas por países vecinos revisionistas. Esto 
que enfatizaban en los conflictos presentes en toda frontera, habida cuenta de la expansión de los Estados vecinos. Siguiendo a Weldes (2009), el problema del uso de estas leyes de aplicación general, mono causales y unidireccionales (ancladas en variables de la geografía física), es que se basan en una epistemología que ignora la centralidad del proceso de interpretación y las condiciones específicas de los casos de estudio y, sobre todo, ignoraban estas particularidades al momento de denominar las amenazas, definidas en lo medular por la condición geográfica de Tarapacá. Las amenazas de "espacios vacíos" y de difícil habitabilidad, serían de la misma índole en Siberia, en la Amazonía, en la Patagonia y en el descampado de Atacama, es decir, en cualquier espacio denominado vacío, aislado o desprovisto de sociabilidad relevante. Así, la ley de áreas valiosas, la ley de ocupación de espacios vacíos y la ley de la reconquista, tuvieron un rol protagónico en orientar las estrategias de desarrollo a seguir, en una región siempre problemática para los intereses del Estado (Von Chrismar, 2000; Mendoza, 2017).

Para el caso de Arica, la ley de las áreas valiosas se aplica por la ubicación geografía óptima de la provincia para conectarse con el Pacífico y el corazón del continente, en vista de nuevas rutas comerciales disputadas por los países limítrofes vecinos revisionistas (Buzeta, 1978). Así lo señala la Estrategia de Desarrollo para Tarapacá en 1985:

En Arica se crean las condiciones óptimas para un corredor de desarrollo: frente portuario, éste, en tanto área valiosa, se constituye en una ambición para Estados limítrofes, ya que representa la mayor conexión del interior de Sudamérica hacia la cuenca del Pacifico.

Por tanto, ante la amenaza potencial se debía planificar el desarrollo ocupando el hinterland, o espacio alimentador del "núcleo vital", concibiendo un crecimiento hasta las mismas fronteras del Tarapacá (Ghisolfo, 1989; Mendoza, 2017). Sin embargo, dicho poblamiento incorpora una nueva arista a la discusión regional no prevista en los gobiernos anteriores, éste debía corresponder -en sus palabras- al ser 'nacional', surgiendo así una discrepancia insalvable en lo referido a la población indígena local. Lo anterior se indica categóricamente en el documento, el que asombrosamente incorpora variables anacrónicas para la época, como la adaptabilidad al clima:

La Ley de Variación de la Frontera y de las Líneas de Menor Resistencia, señalan que la zona rural que representa un 95\% aproximadamente del territorio regional, ofrece las siguientes características: Población indígena vinculada a Perú y Bolivia, idioma aymara y quechua, religión aymara y quechua, idiosincrasia diferente a la chilena de la población aymara e inadaptabilidad climática con la costa, configuración geográfica que

último generaría una competencia entre Estados que iría en desmedro de la soberanía chilena en la región fronteriza. 
diferencia a la zona altiplánica del resto del país "( Estrategia de Desarrollo Regional,1985:11).

Debido a las constantes modificaciones de las fronteras y a las migraciones, prosigue la estrategia, los habitantes de un Estado no coinciden necesariamente con la ciudadanía nacional, en tanto raza (termino usualmente usado por la geopolítica clásica de esa época). Este desequilibrio se debe corregir por distintas vías (educación fronteriza, fijación y asentamiento de las comunidades). Desde la perspectiva organicista del Estado, por tanto, solo hay simbiosis entre sociedad nacional y territorio nacional si hay armonía entre suelo y sangre. Para la geopolítica chilena de la época, suelo y sangre, o la geografía y la raza, son las fuerzas determinantes en el desarrollo y pujanza de los Estados (Sánchez, 2016), vigor que se ponía a prueba en la frontera norte.

En efecto, el dilema geopolítico clave que arrojaban los diagnósticos hechos por las estrategias regionales de la época (Estrategia de desarrollo y seguridad de 1985), surgía de la adscripción identitaria de la población fronteriza. En las regiones periféricas, debía existir plena coincidencia entre la nación y el territorio (territorio nacional homogéneo), entendiendo por ello la preminencia de un pueblo que se haya fusionado racial y culturalmente en torno al ser chileno (Buzeta, 1978: 313), pues aquel tendría la voluntad necesaria para cautelar la soberanía nacional o la transgresión de las fronteras, entre otros desafíos propios de las regiones extremas.

Así, dentro de las fuerzas sociales presentes en las fronteras siempre ha sido un problema geopolítico la adscripción nacional de la comunidad que la habita y transita. Puesto que, desde principios geopolíticos clásicos, las minorías de origen peruano y boliviano, que constituyen "puntas étnicas", han habitado la frontera norte de Chile desde siempre. Aunque poniendo en peligro la seguridad nacional, pues estos grupos no se podrían perfeccionar y no podrían defender el territorio con pujanza, toda vez que no se identifican con el suelo que los alberga. Lo que suponía contrarrestar la heterogeneidad cultural de la frontera (Ghisolfo, 1989).

Dentro de las estrategias geopolíticas que destaca Santana para las fronteras del norte (2013:26), se encuentran las políticas públicas dedicadas a fijar, localizar y registrar a las comunidades aymaras en constante desplazamiento por la franja fronteriza, limitando su movilidad hacia y desde Bolivia y Perú, además de terminar con su pobreza asociada con sus prácticas tradicionales:

En primer lugar, la política a favor de los indígenas de la etnia aymara habitando el espacio de frontera septentrional y en desplazamiento constante entre los territorios limítrofes chileno, boliviano y peruano. La política militar viene a cuestionar la movilidad de esta población ya que la Junta se preocupa en primer lugar del problema de la nacionalidad (chilena) de estas poblaciones. Chilenizar la etnia aymara obliga en primer 
lugar a registrar, localizar y fijar a estas gentes. El Instituto de Desarrollo Indígena tiene en este sentido un papel importante que jugar. El objetivo declarado es, aquí también, productivista: "incorporar estas tierras de las comunidades a la agricultura comercial". Eso implica la destrucción del modo de vida tradicional y por más que uno busque no aparecen los argumentos técnicos o económicos para justificar una tal orientación, sobre todo si se tiene en cuenta la escasa amplitud de la tierra cultivable y el peso minúsculo de la agricultura a escala de toda la región (Santana 2013:26).

Desde perspectivas geopolíticas críticas, al negar la movilidad de estas comunidades, considerándolas "puntas étnicas" o enclaves étnicos, es decir culturas ajenas al ser nacional (en nomenclatura geopolítica), se definen y controlan, concibiéndolos como habitantes circunscritos a áreas limitadas, homogéneas culturalmente, solitarias y estáticas (Shin, 2018). La crítica a esta mirada clásica demuestra la compleja territorialidad de las vidas de sociedades migrantes. En concreto, desde un enfoque de la geopolítica crítica se pone énfasis en develar territorios en constante cambio, reivindicando contextos locales específicos a partir de la creación de lugares transnacionales. Ergo, esta postura nos pone de manifiesto la asociación entre lo personal y lo político, así como las construcciones discursivas de territorios e identidades (Shin, 2018).

Por otro lado, retomando lo referido a la ley de áreas valiosas, desde categorías geopolíticas clásicas se sostenía que el núcleo vital del Estado de Chile ha explotado económicamente de forma limitada el 'espacio de su expansión o hinterland', que constituye el extremo norte (Guisolfo, 1989:227).

Desde una perspectiva geopolítica el valor de estas zonas aisladas debe vincularse con los recursos, con la preservación del espacio nacional por la biodiversidad de éste o por su condición de reserva natural, por la conveniencia de su integración al desarrollo, por la cohesión e identidad nacionales $\mathrm{y}$, fundamentalmente, de la conveniencia de reducir las inequidades que se derivan de una compleja imposición geográfica en beneficio de aquellos ciudadanos que con su esfuerzo colonizan, habitan y configuran la fisonomía de Chile (Fuente-Alba, 2014:8).

Éste último constituye su espacio de expansión por su conexión marítima Pacifica con el sudeste asiático, centrando su poblamiento en las costas e irradiando de forma incipiente hacia el este y siendo irradiado además por los países vecinos. Lo anterior, genera un dilema de seguridad insoslayable para las estrategias de desarrollo vigentes. La cita de 2014, que se expuso anteriormente, refleja la persistente preocupación de la autoridad derivada de la fragilidad geopolítica del extremo norte y sus relaciones con la adscripción identitaria, agregándose el problema ambiental respecto a la preservación de la biodiversidad presente en aquel territorio franqueado por países vecinos. 


\section{La gestión fronteriza del Tarapacá Histórico en los gobiernos post-dictadura.}

Desde la vuelta a la democracia, el Tarapacá Histórico se ha visto sometido a una serie de transformaciones de alcance nacional, debido, entre otras cosas, a su posición geográfica proclive a las conexiones internacionales. Si bien, como se ha insistido, durante la dictadura militar las zonas extremas se posicionaron en la agenda pública principalmente por razones geopolíticas y de seguridad, posteriormente lo han hecho en los diversos instrumentos de gestión pública destacando la dimensión económica de su desarrollo. Sobre todo, mediante diversos instrumentos de excepción e inversión por parte de los gobiernos centrales (Correa y Salas, 2015).

Estos instrumentos, se materializaron desde la década de 1980 a través de normas para la atracción de inversión extranjera, como el Decreto Ley 60018, junto con garantías para la instalación de empresas transnacionales de la gran minería ${ }^{19}$, entre otras acciones (Amilhat Szary, 2013). Estas transformaciones contribuyeron a posicionar a Chile, y particularmente a Tarapacá y en menor medida a Arica Parinacota, en un escenario más abierto al mundo, lo que gravitó en la superación de muchos de los dilemas geopolíticos vistos en los apartados anteriores. Aunque también podemos detectar cierta persistencia de estas visiones clásicas del desarrollo asociadas, sobre todo, a las zonas extremas, pero entroncadas con debates emergentes sobre seguridad, tales como las "nuevas amenazas transnacionales" derivadas del crimen organizado, la migración irregular, el contrabando, el tráfico y la trata de personas (García Pinzón, 2016).

Esta reconfiguración ha dado lugar a la implementación de planes de apertura económica, que han tenido por finalidad valorizar la posición estrategia de Tarapacá. Así, por ejemplo, se observa en la Estrategia de Desarrollo Regional de Tarapacá (2014-2020), en donde los ejes de turismo y comercio, junto con una valoración de su economía extractivista, se declaran como sectores prioritarios para el desarrollo de la región (Gobierno Regional de Tarapacá, 2014). Dicha apertura económica fue parte de una estrategia a nivel nacional en torno a un activo bilateralismo que trajo consigo una serie de Tratados de Libre Comercio (TLC) y diversos acuerdos de complementación económica (Fuentes, 2008).

Sin embargo, aunque los cambios de contexto económico implicaron la renovación de del pensamiento geopolítico, la vigencia de sus principios en las políticas de defensa y exterior

18 El Decreto 600 fue impulsado para promover la inversión extranjera en el territorio nacional mediante derechos de inversión, garantizando certezas y seguridad de carácter jurídico. En:

https://www.economia.gob.cl/1540/articles-185953_documento_1.pdf (visitado el 11-07-2019).

19 Para otros territorios fronterizos de Chile en donde se posicionan actores transnacionales de la minería, Ver: Hevilla, Cristina.; Zusman, Perla. Movilidades y construcción de nuevas territorialidades en la frontera chilenoargentina. Scripta Nova. Revista Electrónica de Geografía y Ciencias Sociales, 2007, vol. XI, n² 245. [ISSN: 11389788]. 
de Chile hacia la frontera norte continuaron presentes en algunos aspectos, aunque conviviendo con nociones renovadas (Carvajal, 2007). Esto se complementa con estudios que muestran que, más allá de los deseos acerca de la superación de la injerencia desmedida del Estado en las poblaciones fronterizas del espacio sudamericano (Linares, 2009), persisten efectos materiales y simbólicos de aquellas estrategias geopolíticas que han dejado huellas visibles (Grimson, 2004:12). De hecho, la apertura económica en lugar de revalorizar estos espacios de diálogo e integración a nivel territorial, subestimaron las políticas activas y de desarrollo de las zonas fronterizas en el marco de la integración de proyectos neoliberales (Sabbatella, 2018).

En este marco, desde la geopolítica clásica, actualmente sigue teniendo validez el clásico axioma que señala categóricamente que, en las regiones fronterizas en tanto zonas extremas, se concentran las fuerzas de los Estados colindantes: aduaneras, policiales, económicas y sociales, expresándose el vigor político del Estado de cara a preservar su integridad territorial en potencial amenaza ante un vecino revisionista (Buzeta, 1978). O, podríamos agregar, ante la emergencia de las denominadas "nuevas amenazas" (Griffiths, 2009). Cabe señalar, que el espacio fronterizo del Tarapacá posee un sentido arraigado de frontera en tanto límite, mucho más marcado que otros territorios, debido a una serie de disputas y litigios que llegan hasta el siglo XXI con demandas en tribunales internacionales que recuerdan el carácter separador de la frontera (Ovando y González, 2018).

En consecuencia, aunque desde la década de 1990 la geopolítica clásica cede terreno como guía de las distintas políticas públicas hacia la geoeconomía ${ }^{20}$, pasando de las rivalidades fronterizas (por límites) a priorizar la competividad económica en este espacio, "la retención del prefijo 'geo' continúa destacando la importancia de la ubicación geográfica en las relaciones internacionales" (Palacio, 2018:89). Este giro refleja el reconocimiento del cambio que se ha producido en las relaciones entre los Estados, en los que predomina las conexiones económicas, bajo las condiciones de la globalización, aunque marcadas por vínculos que oscilan entre la cooperación selectiva y la competencia (Lewis, 2018).

\subsection{Algunos planes de inspiración geopolítica y securitización de agendas fronterizas: nuevas lecturas de la movilidad}

En la agenda de los gobiernos desde la vuelta a la democracia, al alero de la aún vigente Dirección de Fronteras y Limites, DIFROL, creada en 1966 y con escasa renovación en sus prioridades hacia las regiones extremas (Dilla, 2018), la preocupación por la buena gestión de la seguridad en las zonas fronterizas se extiende a través de varias iniciativas públicas, como vernos a continuación, siempre desde una perspectiva de frontera como límite y subestimando su componente como área de desarrollo.

20 El giro hacia la «geoeconomía» refleja el reconocimiento del cambio que se ha producido en las relaciones entre los Estados, en los que predomina las conexiones económicas, bajo las condiciones de la globalización, aunque marcadas por vínculos que oscilan entre la cooperación selectiva y la competencia (Lewis, 2018). 
Siguiendo esta premisa, los gobiernos de la transición ${ }^{21}$ exhibieron una combinación de estrategias de apertura y cierre de fronteras, obligados a mantener una política de fronteras abiertas para los flujos del capital y a repensar la seguridad de aquellos territorios considerados "críticos", en tanto ponen a prueba su estabilidad y atractivo para la inversión extranjera (Ovando y Ramos, 2016). Esta forma de gestionar las fronteras, refuerza un patrón histórico de más larga data, nos referimos a las reformas top down, las cuales fueron concebidas homogéneamente para todo el espacio nacional y decididas, por lo tanto, por las élites gobernantes ${ }^{22}$ sin mayor participación de las comunidades locales (Delamaza, 2012).

En conjunto, un momento significativo, que se registra a partir de los años 90, dando cuenta de la continuidad del fenómeno comenzado en la dictadura y analizado en apartado anterior, es la intensa movilidad fronteriza entre Tarapacá y el sureste boliviano, provocando un creciente interés investigativo por revelarlo (Tapia, 2017; Ramos y Ovando, 2016; Tapia et al., 2017). Esta tendencia, además, se acrecienta con el "efecto llamada" del atractivo económico y que ha desatado la preocupación pública de las autoridades ante la presencia de una migración "descontrolada" de "nuevos migrantes" provenientes de Haití, Venezuela y Colombia, principalmente (Sánchez et al., 2018; Silva et al., 2018; INDH, 2018).

Este fenómeno se debe, dentro de otros factores, a la incorporación de la región de Tarapacá (ya separada de Arica) al mercado mundial a través de la creación de ZOFRI vía reexpedición de sus mercancías a la Macroregión; al fuerte impulso de la actividad minera en la región en las últimas décadas y el impacto de los procesos de integración económica regional, como el impulsado por el Mercosur (Tapia y Ramos, 2013). Acontecimientos que han dado lugar a un intenso movimiento de personas y mercancías en el espacio fronterizo del extremo norte chileno (Aedo, 2017). Sin embargo, han generado tensión con perspectivas y narrativas que abordan la nutrida movilidad, pero centrada en una mirada que vela por la frontera como límite y que se expresa en la representación espacial de las autoridades que cautelan y reordenan permanentemente los espacios fronterizos en función de su utilidad.

Es decir, además de exponer los dilemas geopolíticos tradicionales expuestos en los sucesivos gobiernos, los espacios fronterizos están sujetos a la necesidad de implementar políticas de seguridad y estabilidad que garanticen las transacciones comerciales (Stang, 2016), implementadas con la finalidad de asegurar mayores condiciones de control en el

\footnotetext{
21 La estructura de la transición, muchos de cuyos rasgos imperan hasta hoy, se conformó a partir de un complejo entramado de compromisos y de un mecanismo de negociación permanente entre las elites, donde siempre predominaron los intereses fundamentales de grupos corporativos, tanto informales como institucionales (Fuentes, 2010:106).

22 Este segmento de la población (élites) se ve amenazado persistentemente por el miedo a la pérdida de identidad, lo cual demanda una reafirmación constante de la soberanía nacional, reacciones que se unen al desprecio o al miedo al vecindario y a la carga negativa que tiene la integración regional. aleja de los aspectos puramente comerciales (Fuentes, 2010).
} 
acceso a fronteras terrestres, marítimas y aéreas en la zona norte de Chile (García-Pinzón, 2016; Stefoni y Stang, 2017; Ramos y Tapia, 2019).

Con ello, los diversos gobiernos de la Concertación de Partidos por la Democracia ${ }^{23}$ reclamaron autoridad y capacidad coercitiva en el extremo norte de Chile a través de nuevas leyes, recursos humanos, materiales y tecnológicos para hacer frente a 'nuevas amenazas transnacionales' (Castro, 2014). Así, observamos que el nexo entre movilidad fronteriza y seguridad ha transformado el confín en un potente aparato de control securitario, donde la movilidad humana se presenta como una variable clave (Bigo, 2008). Esta forma de gobierno en las fronteras, también nos recuerda las estrategias geopolíticas de la dictadura ante la movilidad de poblaciones aymaras de la frontera norte y el intento de las autoridades por fijarlas, localizarlas y registrarlas (Santana, 2013). Una reactualización de paradigma que se asocia al tradicional discurso de la seguridad nacional y que tiende a vincular las migraciones con una serie de amenazas estratégicas de carácter transnacional (Stefoni y Stang, 2017). En concreto, el sustrato que guía estas narrativas se sustenta en el marco de la actual legislación migratoria (vigente desde 1975) que concibe a la migración como una eventual amenaza para la seguridad del Estado (Stang, 2016; Quinteros, 2016). Eventual, en la medida que su asentamiento y movilidad circulatoria en torno a las regiones extremas, puede erosionar la relación identitaria con Chile (Ruiz, 2019).

En este escenario, podemos constatar que la agenda fronteriza para Tarapacá se sostiene en base a la expansión de la economía neoliberal y el control de la movilidad humana (Quinteros et al., 2019). Por ejemplo, en Arica se concentra la mayor cantidad de ingresos por paso terrestre del país, aproximadamente seis millones de cruces anuales en el periodo 2010-2014 (Tapia, et al., 2017), lo que ha dado lugar al despliegue de un intenso aparato de control migratorio 24 (García Pinzón, 2016; Ramos y Ovando, 2016) y fronterizo (Ramos, 2018). De este modo, predomina la convivencia de discursos contradictorios que buscan promover políticas de 'frontera abierta' para una migración 'ordenada y regular' y de 'frontera cerrada' para la 'migración ilegal', la trata de personas y el tráfico de migrantes (Quinteros et al., 2019)

Un ejemplo de lo anteriormente señalado, lo constituyen la puesta en marcha del Plan Frontera Norte (2011-2014), el Plan Nacional contra el Narcotráfico (2014-2020) y el Plan Frontera Segura (2018-2022) ${ }^{25}$ y sus alcances particulares en la región, los que combinan

23 Inicialmente, la Concertación estaba compuesta por diecisiete fuerzas políticas que conformaban un amplio espectro, desde la derecha democrática hasta el socialismo, reunidas alrededor de un programa de democratización y estabilidad. Ambos componentes interactuaron en una transición especialmente complicada, donde muchas veces prevaleció el orden sobre la transformación (Fuentes, 2010: 176).

24 Resultado de aquello, es que actualmente, Tarapacá es la región que más expulsa a extranjeros (Quinteros, 2016) Más información: https://www.latercera.com/nacional/noticia/extranjeros-1-750-personas-fueronexpulsadas-chile-tras-condenadas/512406/

25 En virtud de la Ley de transparencia, se solicitó el documento que contiene los lineamientos del Plan Frontera Segura en noviembre del año 2018. Sin embargo, el oficio 2930/2018 de la Intendencia Regional de Tarapacá en 
narrativas securitarias y geopolíticas y últimamente con las derivadas de los compromisos internacionales de los gobiernos de Chile en materia de garantizar derechos y prácticas ancestrales indígenas ${ }^{26}$, como veremos más adelante. Estos planes se orientan hacia el control de amenazas no convencionales provenientes del crimen organizado, el tráfico de drogas y las migraciones irregulares. Para ello, se pretende asegurar mayores rangos de control de acceso a fronteras terrestres, marítimas y aéreas sobre la base de implementación de tecnología, más el concurso de diversas agencias estatales que se coordinan para compartir información, su finalidad es sellar los límites, o anticipar la gestión a diversas fuentes de riesgo derivado del crimen transnacional (Leyton, 2011).

\subsection{Soberanía efectiva y la emergencia de las narrativas de los pueblos ancestrales}

Las ideas que esgrime el Ejército de Chile para sustentar estrategias de defensa y soberanía por parte de las Fuerzas Armadas en las fronteras, buscan propender a una renovada presencia del Estado (representado por el ejército) en las zonas aisladas y extremas mediante la noción de "soberanía efectiva". Su fundamento se encuentra en que las nuevas amenazas aprovechan la débil presencia del Estado en los territorios aislados y zonas extremas, tendiendo a su ingobernabilidad. Estos territorios, por su escasa institucionalidad pública, exponen una soberanía no efectiva. Ergo, fortalecer la presencia estatal se convierte en un objetivo deseado para beneficiar su seguridad (Griffiths, 2009). Cabe destacar que actualmente, como antaño, la presencia efectiva de la soberanía también se centra en la protección de recursos estratégicos ubicados en zonas colindantes de estas las localidades aisladas o "espacios vacíos" y zonas de frontera.

Para materializar esta disposición, en el año 2017 se instaló una unidad militar denominada "Base Militar Patrulla Cariquima27", perteneciente a la VI División del Ejército con asiento en Iquique. La consideramos una iniciativa inédita, pues la seguridad en la frontera es materia tradicional de las policías ${ }^{28}$. Así, en el marco de la denominada soberanía efectiva o

respuesta a la solicitud de acceso a la información señala lo siguiente: "no se entrega por cuanto su conocimiento o publicidad, podría afectar la seguridad de la nación, particularmente si se refiere a la Defensa Nacional o a la mantención del orden público o la seguridad pública, de acuerdo a lo establecido en el número 3, del artículo 21 de la ley 20.285 .

${ }^{26}$ Nos referimos al Convenio Núm. 169 de la OIT sobre Pueblos Indígenas y Tribales, al que adhiere el Estado de Chile a partir del año 2008.

27La comuna de Cariquima se ubica en la región de Tarapacá, a dos horas de Pozo Almonte, a 3.460 metros sobre el nivel del mar y a 15 kilómetros de la línea que separa el territorio chileno con Bolivia. Cuenta con 80 habitantes, una escuela de educación básica y un policlínico, pero carece de suministro de luz eléctrica y agua potable.

28 En julio de 2019, este debate toma ribetes polémicos debido al anuncio del presidente Piñera de otorgarle atribuciones a las Fuerzas Armadas en labores de seguridad fronteriza. El argumento esgrimido por el Gobierno ha sido la necesidad de "aumentar la fuerza y la eficacia en la lucha contra el narcotráfico y el crimen organizado". La Tercera, [Fecha consulta: 19.07.2019] En:

https://www.latercera.com/nacional/noticia/pinera-firma-decreto-darle-atribuciones-las-ff-aa-combatirnarcotrafico-fronteras/734127/ 
la acción del Estado, en términos de seguridad, desarrollo y bienestar, en la totalidad de su territorio (Griffiths, 2009), esta iniciativa proveyó de agua potable y alumbrado a comunas rurales del altiplano chileno y vigilancia efectiva ante las nuevas amenazas, como el contrabando. Así lo recalca el coronel Pablo Onetto Jara, quien participa en esta tarea: "la Base Patrulla instalada en esta localidad del altiplano chileno, tiene la finalidad de marcar presencia militar en zonas aisladas, donde hay compatriotas haciendo soberanía, así ellos sienten que el Ejército les puede prestar un apoyo permanente, y además se sienten seguros" (Núñez, 2016). En concreto, lo que busca esta iniciativa es intensificar el patrullaje militar en territorio chileno para impedir ataques contras civiles, robos, contrabando y narcotráfico provenientes de Bolivia (Eju, 5 de mayo de 2016).

Otro ejemplo de la gestión renovada en las fronteras, es la puesta en marcha de los proyectos Alfil y Cahuelmó en el 2017, financiados ${ }^{29}$ por el Ministerio de Defensa y encabezado por el Ejército de Chile. Estos proyectos, implicaron la compra de 278 camiones para aumentar los rangos de control en estos espacios, inversión estimada en US\$48 millones. Su finalidad es la protección del territorio frente a las amenazas transnacionales y mantener estable el acceso para las rutas comerciales. Así lo señaló categóricamente el Comandante en Jefe del Ejército, General Humberto Oviedo, en un discurso ${ }^{30}$ pronunciado en el marco de la Celebración de las Glorias Navales, en septiembre de 2016:

La institución está comprometida a mantener la "soberanía efectiva" del territorio y los recursos naturales del país, frente a los "riesgos y amenazas trasnacionales latentes" inscritas en las turbulencias regionales e internacionales. Se puede resaltar que estamos insertos en una región de contrastes: por una parte, disponemos de una privilegiada posición geográfica, que permite acceder en condiciones muy favorables a los mercados mundiales, factor que se ve atractivamente incrementado al posibilitar un enorme potencial de bienes proporcionados por la naturaleza. Sin embargo, como contramedida, es un área donde aún perviven conflictos de carácter limítrofe y económico, debido, entre otros motivos, a particulares interpretaciones de tratados, a aspectos ideológicos, como asimismo a intereses comerciales y disputas por recursos naturales compartidos. Es, a no dudar, un espacio que, por los riesgos y amenazas transnacionales latentes, propenso a la inseguridad.

\footnotetext{
29 Cabe señalar que la Contraloría General de la República consideró que la adquisición de este equipamiento fue ilegal debido a que su compra por trato directo no fue debidamente justificada (nota de prensa) [Fecha consulta:25.06.2019].En:https://www.diarioconstitucional.cl/noticias/asuntos-de-interespublico/2019/04/14/cgr-determina-que-causal-invocada-por-ejercito-para-celebrar-trato-directo-no-seencuentra-justificada/ (visitado el 25/06/2019).

30 Ejército demanda ejercer "soberanía efectiva" para proteger territorios y recursos naturales. Discurso de Comandante en Jefe del Ejército [Fecha consulta: 30.06.2019] En: https://msiainforma.org/es/exercito-chilenoadverte-sobre-soberania-efetiva-para-resguardar-territorio-e-recursos/
} 
Los casos anteriormente descritos, dan cuenta de la persistencia de discursos geopolíticos clásicos pero reeditados por la emergencia de nuevas amenazas y por contribuir a cautelar los recursos naturales estratégicos.

Finalmente, respecto a la articulación entre narrativas y prácticas securitarias con geopolíticas y, últimamente, con las derivadas de los compromisos internacionales de los gobiernos de Chile en materia de garantizar derechos y prácticas ancestrales indígenas, resultan muy ilustrativos los incidentes ocurridos en el Complejo aduanero de Colchane y Pisiga en Julio de 2019, a propósito de la implementación del Plan Frontera Segura y el cierre de cruce ancestrales que unen a las comunidades fronterizas de Colchane y Pisiga. Las comunidades indígenas reivindicaron el convenio $\mathrm{N}^{\circ} 169$, parte VII que señala ${ }^{31}$.

Los gobiernos deberán tomar medidas apropiadas, incluso por medio de acuerdos internacionales, para facilitar los contactos y la cooperación entre pueblos indígenas y tribales a través de las fronteras, incluidas las actividades en las esferas económica, social, cultural, espiritual y del medio ambiente.

Guillermo Moscoso, líder de la junta vecinal de Cariquima, al fragor del conflicto señaló categóricamente que existe inquietud y malestar por la medida adoptada a nivel central, ya que no se consideró el derecho de los pueblos originarios -como el aymara- al libre tránsito entre fronteras: "Nuestra comunidad está de acuerdo con que se protejan las fronteras, pero dentro de la comuna también hay costumbres" (...) "una de esas tradiciones es una feria que se realiza periódicamente entre las comunidades limítrofes de Chile y Bolivia, donde se comercializan alimentos básicos" (Estrella de Iquique, 17 de julio de 2019, pág. 2)

La solución propuesta por la comunidad es reabrir el paso, no formal, ubicado a 200 metros al sur del complejo fronterizo Colchane, así como flexibilizar el control del cruce. La idea es realizar un control por el camino ancestral solo con cédula de identidad, para así evitar la burocracia del paso fronterizo.

Por su parte, el Gobierno Regional de Tarapacá, días antes, se manifestó sobre el tema junto a senadores de la región, el Subsecretario del Interior, además de funcionarios de la DIFROL, a través de la Unidad de Pasos Fronterizos. Plantean flexibilizar el Plan Frontera Segura como solución a este impasse con la comunidad y proponen implementar un sistema que permita mantener la movilidad vecinal ancestral entre los pobladores de Colchane y Pisiga. Esta iniciativa se trata de una preocupación inédita para estas autoridades y en la que, además, sorpresivamente se involucra directamente un equipo de la Unidad de Pasos

31 Ministerio de Desarrollo Social, Documento sobre pueblos indígenas y Tribales, pp, 32. [Fecha consulta: 04.07.2019] En: https://www.mop.cl/asuntosindigenas/Documents/convenio169.pdf 
Fronterizos de la DIFROL ${ }^{32}$. Además, resulta interesante que las autoridades relacionen este impasse con la alta demanda que tiene el complejo fronterizo integrado Colchane-Pisiga, el cual, durante el 2019, indica el comunicado del Gobierno Regional, ha aumentado en 39\% en la carga de camiones, $11 \%$ el transporte de pasajeros y un $22 \%$ en el tránsito vehicular según las estadísticas de Aduanas.

Por su parte, el Intendente de Tarapacá, recalcó que, "vamos a hacer todo lo que esté a nuestro alcance como Gobierno para dar mayor seguridad a nuestros compatriotas (...), la ciudadanía nos ha pedido que así sea y nuestro Gobierno está prestando la mayor atención a este tema" (Estrella de Iquique, 17 de julio 2019, pág.2). La autoridad también apuntó a incentivar el diálogo con las comunidades, en vista de "poner en valor, tanto la cultura ancestral, como la necesidad de seguridad", respondiendo así a los imperativos del Plan Frontera Segura. El Consejero Regional Eduardo Mamani, en la misma línea, señaló una postura conciliadora pero compleja en su práctica: “El objetivo (...), es aterrizar el Plan Frontera Segura a la realidad del pueblo aymara, pues hay una "relación ancestral de convivencia" en la frontera altiplánica" (Estrella de Iquique, miércoles 17 de julio, p.3).

Aludimos más arriba, que iniciativas tales como algunas disposiciones del Plan Frontera Segura, buscan controlar la movilidad fronteriza, imponiendo los temas de seguridad a cualquier otra forma de concebir el territorio. De este modo, la constante presencia de una movilidad flotante fronteriza se considera una eventual amenaza. En efecto, como señala el "Plan Maestro Parinacota: un impulso de política exterior", dentro de las preocupaciones de las políticas públicas hacia las fronteras interiores (Masalleras y Ortega, 2013), el diagnóstico revela la decepción de su población con el Estado y el rol de las comunidades nativas con demandas de autonomía en curso (Ruiz, 2019), Así, los problemas identificados en el altiplano chileno, como el acontecido en el complejo fronterizo de Colchane, constituye un ejemplo singular que deja en evidencia, con meridiana claridad, que la creciente movilidad transfronteriza aunque no constituye una amenaza militar evidente (sí potencial dados los litigios pendientes ${ }^{33}$ ) como antaño, sí pone en riesgo la seguridad en varios frentes, pues en su trama confluyen el contrabando, la migración irregular y las demandas ancestrales al amparo de compromisos internacionales suscritos por el Estado de Chile. Dentro de éstos, hemos destacado la seguridad cultural que brinda la homogeneidad nacional y la amenaza foránea a la identidad y pertenencia (Heyman, 2006).

Con todo, destacamos que se ha retornado a la movilidad aymara como fuente de eventual amenaza en la frontera norte, tema ya abordado en estrategias de desarrollo de la dictadura. Se trata de una amenaza eventual, en la medida que su escaso asentamiento y movilidad,

32 Gobierno Regional de Tarapacá, 2019. Comunicado de prensa “Habilitarán mecanismo para el tránsito vecinal en Colchane, ) [Fecha consulta: 17.07.2019] En: https://www.goretarapaca.gov.cl/habilitaran-mecanismo-paratransito-vecinal-en-colchane/ (visitado 17-07-2019)

33Persiste el litio en La Haya por el rio Silala 
que se entremezcla con migrantes y contrabandistas, puede erosionar la relación identitaria con el territorio nacional.

\section{Conclusiones}

En los sucesivos gobiernos de Chile desde la dictadura a la actualidad, la inspiración geopolítica, con variantes y matices, ha inspirado las estrategias regionales y planes que han gobernado la frontera norte de Chile. Esta tendencia ha traspasado las configuraciones político/ideológicas que han cruzado el espectro político nacional, sin diferencias sustantivas (Dilla, 2019). En particular, la dictadura, su insistente narrativa geopolítica y varias de sus iniciativas diseñadas para el norte, estuvieron dirigidas a negar la frontera como realidad sociocultural, cautelando el componente nacional de su población y controlando su movilidad en busca de una sobredimensionada cohesión identitaria que persiste, aunque con matices y de manera mucho más limitada desde la vuelta a la democracia, como intentamos demostrar con la evidencia expuesta, hasta hoy.

Así, la aplicación de leyes geopolíticas contenidas en la Estrategia de Desarrollo de Tarapacá de 1985, dejan en evidencia que, al tratarse los problemas de la región, se intentó hegemonizar y proyectar una imagen espacial nacional sobre otras posibles existentes en el ámbito regional- fronterizo. Ésta se situó desde la noción y representación derivada de las fronteras interiores, espacios vacíos, territorios inhóspitos de difícil habitabilidad, puntas étnicas, entre otros vocablos. Como consecuencia, los imaginarios geográficos contenidos en estos conceptos devienen en una pugna entre una representación del espacio oficial, impuesto por la maquinaria estatal de la época, y los espacios de representación construidos por una gama de actores sociales, subalternos (Lefebvre, 1974). Es el caso de las comunidades aymaras tarapaqueñas y municipios rurales que tuvieron y tienen una mirada del espacio y una identidad resultado de sus cambiantes trayectorias espaciales, en donde el componente transfronterizo desde y hacia Perú y Bolivia es clave (Ovando y González, 2018).

En suma, no ha existido una perspectiva de desarrollo sustantiva, desde los sucesivos gobiernos desde 1974, inspirada en la realidad particular de las zonas fronterizas, subestimando los probables efectos sinérgicos de las dinámicas marcadas por su movilidad y presencia de habitantes (Dilla, 2018), como es el caso de posibles proyectos de cooperación para el desarrollo de estos territorios diseñados desde las mismas comunidades insertas en la globalización (Rouvière, 2014). De este modo, las formas de gestión pública de los territorios del extremo norte, donde primaron criterios históricos de soberanía y seguridad, han contemplado de una manera limitada las fronteras como espacios donde es posible su desarrollo. De hecho, actualmente existe un amplio debate sobre la fortificación de las fronteras y su función, en muchos casos más teatral que efectiva, pero que sin duda afecta a personas desesperadas por querer cruzarlas y habitarlas (Ramos y Tapia, 2019). Todo ello en el marco de nuevas políticas de control fronterizo, como el Plan Frontera Segura, que 
hacen de las fronteras una realidad que se reinventa en su intento de cerrarse y abrirse de una forma a veces sutil y sofisticada y, en otras ocasiones, de manera teatral (Brown, 2015).

Esta apreciación se expresa en discursos hegemónicos que buscan representar estos espacios del norte de Chile como problemáticos y un dilema para el Estado. Así, desde la geopolítica crítica se sostiene que los espacios de la política fronteriza, en tanto parte de la trama de la política internacional, se "producen" en representaciones que se visibilizan en diferentes tipos de planes estratégicos e imaginarios que los sustentan y que hemos revisado a lo largo de este trabajo. Estos imaginarios espaciales revisados proporcionan marcos cognitivos que dan sentido a los eventos analizados. En este contexto, desempeñan un papel importante al establecer límites entre ellos, los extranjeros y comunidades indígenas en constante movilidad, y nosotros, los nacionales y la autoridad (O tuathail y Dalby, 1998). Creemos que identificar y analizar estos imaginarios geopolíticos de manera crítica, puede contribuir a una mejor comprensión de la política que los gobernantes adoptan, toda vez que permite ponderar el valor que se les asigna a los habitantes que circulan en estos territorios móviles.

\section{Bibliografía}

Aedo, Angel. "Encarnando (in)seguridad. Orden policial y política de la presencia en la frontera norte de Chile". Antípoda. Revista de Antropología y Arqueología, N²9, pp. 87-103, 2017.

Agnew, John. "The territorial trap: the geographical assumptions of international relations theory". Review of International Political Economy. vol. 1 num. 1, 53-80, 1994.

Agnew, John. "The origins of critical geopolitics" en J. Sharp, K. Doods y M. Kuus (eds). The Ashgate research Companion to Critical Geopolitics. Farnham: Ashgate, 19-32, 2013.

Amigo, Catalina. "No estamos lejos, allá están lejos". Perspectivas locales sobre aislamiento. En: Imaginarios geográficos, prácticas y discursos de frontera. Aisén patagonia desde el texto de la nación. Andrés Núñez, Enrique Aliste, Alvaro Bello, Mauricio Osorio (eds), pp167190) Lom ediciones, Santiago, 2017.

Amilhat Szary, Anne-Laure. Minas en la montaña: Cuando la explotación de las periferias escapa al Estado, Andrés Núñez - Rafael Sánchez - Federico Arenas (eds). En: Fronteras en movimiento e imaginarios geográficos: la cordillera de Los Andes como espacialidad sociocultural, pp.221-242, Santiago de Chile, Instituto de Geografía, Pontificia Universidad Católica de Chile, RIL, 2013.

Benedetti, Alejandro. "Espacios fronterizos del sur sudamericano. Propuesta de un modelo conceptual para su estudio", Estudios Fronterizos, vol. 15 núm. 29, 11-47, 2014.

Bigo, Didier. "Globalized (in) Security: the Field and the Ban-opticon". Review Terror, insecurity and liberty: illiberal practices of liberal regimes after. vol. 9, N¹1, pp. 10-48, 2008.

Borquez, A. "La regionalización, un enfoque geopolítico" Seguridad Nacional, Academia Superior de Seguridad Nacional, num. 20, 39-58, 1981. 
Bravo, L. "Bolivia, Visión personal de un enigma geopolítico", Seguridad Nacional, Academia Superior de Seguridad Nacional, num. 23, 25-44, 1982.

Brown, Wendy. Estados amurallados, soberanía en declive, Herder Editorial, 2015.

Carvajal, Patricio. "Geopolítica de los entornos y sociedad del riesgo. Una interpretación desde la geopolítica crítica. El caso chileno". Revista Política y Estrategia, Nº108, pp. 46-70, 2007.

Buzeta, Oscar. Chile geopolítico: presente y futuro. Santiago, CISEC, 1978.

Cairo, Heriberto. "Elementos para una geopolítica crítica tradición y cambio en una disciplina maldita", Ería: Revista cuatrimestral de geografía, num. 32, 195-213, 1993.

Cairo, Heriberto y Lois, María. Geografía política de las disputas de fronteras: cambios y continuidades en los discursos geopolíticos en América Latina (1990-2013). Cuadernos de Geografía: Revista Colombiana de Geografía, [S.1.], v. 23, n. 2, p. 45-67, jul. 2014.

Cabrera Laster. "La relación bilateral Chile-Perú: un caso de visiones geopolíticas opuestas" Revista Encrucijada Americana, vol. 3, num 1, 46-63, 2009.

Cabrera Laster. "Complejidades y desafíos en la relación entre Chile y Perú en el siglo XXI: un enfoque desde la geopolítica crítica", Revista Relaciones Internacionales Escuela de Relaciones Internacionales. Universidad Nacional, Costa Rica, num. 89, 109-124, 2016.

Cabrera, Lester. La construcción de la geopolítica en Suramérica: puntos de encuentro y desencuentro de una disciplina relegada. Análisis Político, [S.1.], v. 31, n. 94, p. 175-192, 2018. Canessa, J. "Visión geopolítica de la regionalización chilena", Seguridad Nacional, Academia superior de la seguridad nacional, num. 24, 13-36, 1982.

Canessa, J. "Visión geopolítica de la regionalización chilena" en: Meirelles, Carlos. (ed.). Antología geopolítica de autores militares chilenos. Santiago de Chile, Centro de Estudios e Investigaciones Militares, 215-235, 2000.

Castro, Luis. "Imaginarios y chilenización: los agentes fiscales chilenos y su visión del espacio y la población andina de la provincia de Tarapacá, norte de Chile 1880-1918/". Anuario de Estudios Americanos, 71(N²), pp. 661-690, 2014 a.

Chateau, Jorge. Características principales del pensamiento geopolítico chileno. Análisis de dos libros. Documento de Trabajo Flacso, Chile, 1997

Chateau, Jorge. "Regionalización y geopolítica. Algunas reflexiones". FACSO, D.T, num. .75-78, Santiago, 1978.

Child, John. "Pensamiento geopolítico y cuatro conflictos en Sudamérica". Ciencia Política, vol 3, num. 1-2, 71- 104, 1981.

Claval, Paul. "Comment s'organise l'espace régional”. Sciences Humaines, Hors série, Région et mondialisation, N8, pp.6-8, 1995.

Correa, Loreto. "Políticas públicas y gobernabilidad en las zonas extremas de Chile, 20102012". Estudios de Seguridad y Defensa, núm. 1, 2013.

Correa, Loreto y Avellaneda, C. "Conectividad, política exterior y seguridad en la región de Magallanes y Antártica Chilena y la Región de Arica y Parinacota”, en Alejandro Salsas y Loreto Correa (eds) Gobernabilidad, desarrollo y seguridad en las zonas extremas de Chile, Colección de Investigaciones Academia Nacional de Estudios Políticos y Estratégicos, num. 37, 159-208, 2015. 
Correa, Loreto y Salas, Alejandro. Gobernabilidad, Seguridad y Desarrollo en las zonas extremas en Chile. Edición ANEPE, Santiago de Chile, 2015.

Dalby, Simón. Geopolitics, the revolution in military affairs and the Bush doctrine. International Politics, 46(2-3), 234-252, 2009.

Detlef, Nolte y Wehner, Leslie. Geopolitics in Latin America, Old and New, In: David R. Mares and Arie M. Kacowicz (Eds.). Routledge Handbook of Latin American Security New York, 2016.

Delamaza, Gonzalo. “Agendas de política social y construcción democrática en la transición chilena". Revista de Gestión Pública, 1, N², pp. 311-386, 2012.

Dilla, Haroldo. "El regímen politico fronterizo en Arica: más allá de la garita", en: Dilla, Haroldo y Álvarez, Camila. La vuelta de todo eso. Economía y sociedad en la frontera chileno/peruana: el complejo urbano transfronterizo Tacna/Arica. Santiago de Chile: RIL Editores, 2019.

Dilla, Haroldo y Álvarez, Camila. La vuelta de todo eso. Economía y sociedad en la frontera chileno/peruana: el complejo urbano transfronterizo Tacna/Arica. Santiago de Chile: RIL Editores, 2019.

Fuente-Alba Poblete, J.M. “Zonas aisladas y extremas: una visión institucional para la soberanía efectiva". Escenarios Actuales. Centro de Estudios e Investigaciones Militares Santiago de Chile, vol. 19, N¹.pp. 5-12, 2014.

Fuentes, Claudio. "Fronteras calientes". Latinoamérica, vol.8, N³ (2008), pp. 12-21.

Fuentes, Cristian. "Progresismo y política exterior de Chile. Consenso progresista. Política exterior de los gobiernos progresistas del Cono Sur": convergencias y desafíos., pp. 97, 2010.

Fuente-Alba, Juan. “Zonas aisladas y extremas: una visión institucional para la soberanía efectiva". Escenarios Actuales. vol. 19, N¹, pp. 5-12, 2014,

Galdames, Luis y Ruz, Rodrigo. "La junta de adelanto de Arica y John V. Murra: dos lecturas sobre el desarrollo andino en el norte de Chile." Chungará (Arica) 42, N¹, pp. 257-270, 2010. Ghisolfo Araya, F. (1989) “El Norte Grande: análisis geopolítico y perspectivas" Colección Terra Nostra, num. 14, Instituto de Investigaciones del Patrimonio Territorial de Chile, Universidad de Santiago de Chile, 223-234.

García-Huidobro, F. (1978) “Geopolítica Chilena y Seguridad Nacional”. Seguridad Nacional, Academia Superior de Seguridad Nacional, núm. 10, 17-38.

García Pinzón, Viviana. "Estado y frontera en el norte de Chile". Revista de Estudios Fronterizos, nueva época, 16, N³1, pp. 117-148, 2015.

García, Pinzón, Viviana. “Territorios fronterizos: Agenda de seguridad y narcotráfico en Chile: El Plan Frontera Norte”. Estudios internacionales (Santiago), 47, N¹81, pp. 69-93, 2016. González, Sergio. "La zona franca de Iquique y su perspectiva industrial: un dilema regional". Revista EURE 18, No54, 79-90, 1992.

González, Sergio. Las históricas relaciones entre Tarapacá y Oruro: la frustrada tentativa de integración transfronteriza durante ciclo de expansión del salitre (1864-1928). Rev. geogr. Norte Grande. n.50 pp.63-85, 2011.

González, Sergio. "La hoja transfronteriza. El consumo de coca en las faenas mineras salitreras en el Norte Grande de Chile (1900-1930)". Historia Crítica, N59, pp. 101-121, 2016. 
Grimson, Alejandro. "Fronteras, estados e identificaciones en el Cono Sur", en: Cultura, politica y sociedad Perspectivas latinoamericanas. CLACSO, Consejo Latinoamericano de Ciencias Sociales, Ciudad Autónoma de Buenos Aires, Argentina, , p. 127-142, 2005.

Griffiths, John. "Chile y los Desafíos Globales de Seguridad" UNISCI Discussion Papers, No 21, pp. 14-26, 2009.

Ghisolfo Araya, Francisco. "El Norte Grande: análisis geopolítico y perspectivas" Colección Terra Nostra, num. 14, Instituto de Investigaciones del Patrimonio Territorial de Chile, Universidad de Santiago de Chile, 223-234, 1989.

Hepple, Leslie. "The revival of geopolitics", Political Geography Quarterly, № 5, pp.21-36, 1986.

Guerrero, Néstor. Algunas reflexiones sobre el concepto "soberanía". Aportes para el debate de política exterior en Chile ESD. Estudios de Seguridad y Defensa No 3. Pp. 189-204, 2014 Harms, Carlos. Los grandes problemas de la zona norte de Chile. Santiago: La Ilustración. 1930.

Harvey, David. Spaces of Capital Towards a Critical Geography, Published by arrangement with Edinburgh University Press, Edinburgh, 2001.

Huneeus, C. (1994) "La transición ha terminado", Revista de Ciencia Política (Santiago de Chile), vol. 16, num. 1-2, 33-40.

Heyman, Josiah. "Cuatro temas en los estudios de la frontera contemporánea”. En: Ribas, N. (eds) El Río Bravo Mediterráneo. Las regiones fronterizas en la época de la globalización. Barcelona: Bellaterra, pp. 81-97, 2011.

Icarte, Luz, Torres., Natalia y Ramos, Romina. "La Zona Franca de Iquique y su impacto en el trabajo informal de mujeres migrantes fronterizas". Polis (Santiago), 17(51), 63-87, 2018. Iturriaga, Jorge. Seguridad nacional y algunas interrelaciones, Universidad de Tarapaca, Chile, 1983.

Jiménez, D. “Desde el Tratado de Paz y Amistad de 1984 al Tratado de Maipú de 2009: Un proceso evolutivo institucionalmente consolidado". Revista de ciencia política (Santiago), vol. 36, num. 2, 523-540, 2016.

Lassault, Michel. El hombre espacial. Editorial Amorrotus, Buenos Airesm, 2015.

Lefebvre, Henri. La production de l'espace, Anthropos, Paris, 1974.

Leyton, Cristián. Chile y Perú: una rivalidad duradera. Santiago de Chile: Ediciones Akhilleus, 2011.

Linares, María Dolores. "Un puente en la zona transfronteriza: representaciones sociales, identidades y conflicto. El caso Posadas-Encarnación". Estudios fronterizos, vol.10, N²0, pp. 47-77, 2009.

Lewis, David. Geopolitical Imaginaries in Russian Foreign Policy: The Evolution of 'Greater Eurasia', Europe-Asia Studies, 70, Nº10, pp. 1612-1637, 2018.

Masalleras, Marcelo y Ortega, Rodolfo."Fronteras interiores; una contribución del ejército vigente 135", Memorial del Ejercito de Chile, N488, pp. 135-147, 2012.

Masalleras, M. y Ortega, R. (2012) “Fronteras interiores; una contribución del ejército vigente 135", Memorial del Ejercito de Chile, num. 488, 135-147. 
Mendoza, Juan. Razonamiento Geopolitico. Construcción de Representaciones y Códigos Geopoliticos de Chile y sus vecinos. Concepción, Chile: Sello editorial Universidad de Concepción, Cuadernos Atenea, 2017.

Mercado, Edgardo. “La Guerra de los Puertos". Revista Caretas, N¹399, 1996.

Nogué Font, J. y Vicente Rufi, J. Geopolítica, identidad y globalización. Barcelona: Ariel; col. Ariel Geografía, 2001.

Núñez, Andrés. "El país de las cuencas: fronteras en movimiento e imaginarios territoriales en la construcción de la nación. Chile siglos XVIII-XIX". Scripta Nova. Revista Electrónica de Geografía y Ciencias Sociales XVI, vol. 16, num. 418, 2012.

Núñez, Cristian. "Cariquima valora Base Militar fronteriza con Bolivia: comunidad era permanentemente robada" Nota de prensa (2016) [Fecha consulta: 20.07.2019] En: https:// www.biobiochile.cl/noticias/2016/04/14/cariquima-valora-base-militar-

fronteriza-con-bolivia-comunidad-era-permanentemente-robada.shtml

O`tuathail, G. y Dalby, S. "Introduction. Rethinking Geopolitics. Toward a critical geopolitics", Rethinking Geopolitics, New York: Routledge, 1-38, 1998.

Olguín, Jorge. La derecha chilena y los principios legitimadores del pre y post golpe de Estado de 1973. Izquierdas, №38, pp. 141-163, 2018.

Olguín, Jorge. "Razón teológica para la implantación instrumental del neoliberalismo en Chile bajo la dictadura civil militar, 1973-1982". Cuadernos de Historia, № 49, pp. 195-220, 2019.

Ovando, Cristian y Ramos, Romina. "Imaginarios geográficos en torno a la franja fronteriza de Tarapacá: el Estado y los habitantes/migrantes". Scripta Nova, revista electrónica de geografía y ciencias sociales. vol.20, N529, p.2, 2016.

Ovando, Cristian, y González, Sergio. “El papel de la paradiplomacia entre el norte de Chile y el sur del Perú: antecedentes históricos, limitaciones institucionales y nuevos desafíos “Posfallo de La Haya”. Diálogo Andino, N55, pp. 79-91, 2018.

O'tuathail, G. y Dalby, S. "Introduction. Rethinking Geopolitics. Toward a critical geopolitics", Rethinking Geopolitics, New York: Routledge, 1-38, 1998.

Palacio, Priscila. La geopolítica argentina relegada por condiciones domésticas (2001-2017). Una mención al caso de la Triple Frontera. Anuario latinoamericano, Ciencias Políticas y Relaciones Internacionales, 2018.

Pittman, Howard.Algunas tendencias geopolíticas especificas en los países del ABC. Nuevas aplicaciones de la ley de las áreas valiosas. Revista de Ciencia Política, vol. 3, N 1-2, pp. 27-70, 1981.

Podestá, Juan. La Invención de Tarapacá, Estado y Desarrollo Regional en Chile. Ediciones UNAP, Iquique, Chile, 2004.

Porcaro, Tania. "Representaciones, Narrativas e Imaginarios De Las Fronteras Estatales. Análisis De Las Cartografías Turísticas y Las Formas De Imaginar La Triple Frontera Circumpuneña." Fronteras en perspectiva / perspectivas sobre las fronteras (Salizzi y Barada comps, 2019. 
Quinteros, Daniel. “¿Nueva “crimigración” o la vieja economía política del castigo? Dos aproximaciones criminológicas para entender el control punitivo de la migración en Chile", Astrolabio, N¹7: pp. 81-113, 2016.

Quinteros, Daniel; Dufraix, Roberto y Ramos, Romina. "Human Trafficking Cases in Chile: Challenges for Reducing the "Dark Figure", En: Winterdyk J., Jones J. (eds) The Palgrave International Handbook of Human Trafficking Palgrave Macmillan, Cham, 2019.

Quiroz, Rodolfo y Narváez, Ángelo. “De la loca geografía de Mistral a la geografía militar de Pinochet". Rev. Geografía Valpso (En línea), No 49, | ISSN 0718 - 9877, pp. 30-54, 2014.

Quiroz, Diego., Díaz, Alberto., Galdames, Luis y Ruz, Rodrigo. Campesinos andinos y políticas agrarias durante la Junta de Adelanto de Arica (Azapa, Lluta y la precordillera, 1959-1976). Idesia (Arica), 29, N², pp. 157-168, 2011.

Ramos, Romina y Ovando, Cristian. "La región de Tarapacá: Seguridad fronteriza y múltiples apropiaciones de su espacio". Revista polis, №43, p. 2-19, 2016.

Ramos, Romina. "Entre poder y resistencias: análisis de las movilidades no territoriales en la zona fronteriza de la región de Tarapacá". Diálogo andino, N57, p. 87-98, 2018.

Rouvière, Leatitia, “Gobernar territorialidades transfronterizas. Seguridad y "desarrollo con identidad" aymara en la triple frontera del norte de Chile (Chile-Perú-Bolivia)", Trace, N65, pp. 37-50,2014.

Ruiz, Roberto. Zonas extremas continentales y política exterior: un escenario estratégico e impostergable para Chile. Trabajos prospectivos de MIDIPLAN. Dirección de Planificación Estratégica del Ministerio de RR.EE, Santiago, 2019.

Ríos, Marcelo. Política y propuestas de desarrollo de Arica desde 1930 a 1973. Iquique, CREAR, Chile, 1992.

Ruz, Rodrigo., Galdames, Luis y Díaz, Alberto. Junta de Adelanto de Arica, (1958-1976), Experiencia, Documentos e historia regional. Ediciones Universidad de Tarapacá, 2015.

Stang, Fernanda. “De la Doctrina de la Seguridad Nacional a la gobernabilidad migratoria: la idea de seguridad en la normativa migratoria chilena, 1975-2014". Polis (Santiago), vol.15, N44, pp. 83-107, 2016.

Shin, Haeran. "The territoriality of ethnic enclaves: dynamics of transnational practices and geopolitical relations within and beyond a Korean Transnational Enclave in New Malden", London, Annals of the American Association of Geographers, 108, №3, pp. 756-772, 2018.

Sabbatella, Ignacio. "Neoliberalismo e integración" de hecho" en el Cono Sur: Argentina como exportadora de hidrocarburos". Desafíos, 30, N¹, pp. 173-212, 2018.

Sánchez, Katherin., Valderas, J., Messenger, Karen., Sánchez, Carolina y Barrer. Haití, la nueva comunidad inmigrante en Chile. Rev. chil. pediatra., vol.89, N.2, 2018.

Sánchez, Marcelo. Las Antigüedades de un pequeño dictador. Imaginarios de lo Antiguo en Geopolítica de Augusto Pinochet. En: II Jornada de Humanidades: El Mundo Clásico y su trascendencia en la actualidad. Pensando a los Clásicos para Latinoamérica. 28, 29 y 30 de noviembre de 2016, Santiago, Departamento de Historia, Universidad de Santiago de Chile, USACH, 15 págs, 2016.

Santana, Roberto. "Control del espacio y control social en el Estado militar chileno" Revista de Geografía Espacios Vol. 3, N6, pp.13-28, 2013. 
Santillana, Arturo. Apuntes para una genealogía del Estado. Argumentos (México, D.F.), 23(64), 89-104, 2010.

Santis, Hernan." El pensamiento geográfico-político de Ratzel en la geopolítica chilena”. Revista de Geografía Norte Grande, vol. 25, N²5-27, pp. 135-140, 1998.

Sanz, Jorge. De la geopolítica global al desarrollo local Ocupación y Desarrollo del Espacio de Crecimiento en Chile Estudio de Caso: Región de Arica-Parinacota. Tesis (Doctorado en Desarrollo Local y Territorio), Universitat Jaume I. Instituto Interuniversitario de Desarrollo Local. España, 2014.

Silva, Jimena., Ramirez, Francis y Zapata, Pamela. "Experiencias laborales de mujeres migrantes afrocolombianas en el norte de Chile". Interciencia, vol. 43, núm. 8, pp. 544-551, 2018.

Sohn, C. "Modelling cross-border integration: The role of borders as a resource". Geopolitics, num. 19, pp. 587-608, 2014.

Soza-Amigo, Sergio y Correa, Loreto. Regiones extremas chilenas y su invisibilidad económica. Si Somos Americanos, 14(2), 187-216, 2014.

Serje de la Ossa, M. (2017) “Fronteras y periferias en la historia del capitalismo: el caso de América Latina". Revista de geografía Norte Grande, num. 66, pp. 33-48, 2017.

Stefoni, Carolina y Stang, Fernanda. "La construcción del campo de estudio de las migraciones en Chile: notas de un ejercicio reflexivo y autocrítico". Íconos. Revista de Ciencias Sociales, (58), 109-129, 2017.

Tapia, Jorge. "La Macroregión del Centro Oeste y el Pacífico de América del Sur y el APEC”, en Moyano, Eduardo (ed.) "Chile y APEC. Postítulo a distancia para diplomáticos", Santiago, pp. 412-413, 2004.

Tapia Jorge. Terrorismo de Estado, Ciudad de México, Editorial Nueva Imagen, 1980.

Tapia, Marcela y Ramos, Romina. "Mujeres migrantes fronterizas en Tarapacá a principios del siglo XXI: El cruce de las fronteras y las redes de apoyo". Polis (Santiago), vol.12, N³5 (2013), pp. 229-257, 2013.

Tapia, Marcela y Chacón, Fernanda. "Vínculos transfronterizos: vida, movilidad y comercio en el barrio boliviano de Iquique, Chile". REMHU: Revista Interdisciplinar da Mobilidade Humana. 24, N47, pp. 131-152, 2016.

Tapia, Marcela. "Las fronteras, la movilidad y lo transfronterizo: Reflexiones para un debate". Estudios Fronterizos, vol. 18 N³7, pp. 61-80, 2017.

Tapia, Marcela., Liberona, Nanette y Contreras, Yasna. "El surgimiento de un territorio circulatorio en la frontera chileno-peruana: estudio de las prácticas socio-espaciales fronterizas". Geografía Norte Grande, N66, pp.117-141, 2017.

Taylor, H. "Análisis geopolítico de las Falklands". Revista chilena de geopolítica. vol.3, num. 3, 25-68, 1987.

Urrutia Reveco, S. El sueño por una carretera: Carretera Austral, representaciones sociales y geopolítica durante la dictadura militar chilena, 1973-1990.

<http:/ / repositorio.uchile.cl/handle/2250/143752> , 2016.

Valdivia, Verónica y Donoso, Karen. La alcaldización de la política. Los municipios en la dictadura pinochetista. Santiago: LOM, 2012. 
Vidal, Felipe. "La Genealogía como Método y el uso Genealógico de la Historia”. A Parte Rei: revista de filosofía, N²9, pp. 8, 2003.

Van Kessel, Juan. “Los aymaras bajo el Régimen Militar de Pinochet (1973-1990)”. Cuaderno de Investigación Social, N²9, pp.170-186, 1990.

Von Chrismar, Julio. "Algunas definiciones y alcance de la Geopolítica”. Seguridad Nacional. Academia superior de Seguridad Nacional, núm.14, 7-. 1979.

<https://www.anepe.cl/wp-content/uploads/EDICIÓN-No-14-COMPLETA.pdf>

Von Chrismar, Julio. "Reflexiones acerca de algunos problemas territoriales y fronterizos de chile. Del morro de Arica al monte Fitz Roy", Anales de Historia Militar, pp. 92-120, 1993.

Von Chrismar, Julio. “Geopolítica. Leyes que se deducen del estudio de la expansión de los Estados". Santiago de Chile, Memorial del Ejército, en: Meirelles, Carlos (ed.) Antología geopolítica de autores militares chilenos. Santiago de Chile, Centro de Estudios e Investigaciones Militares, 2000.

Von Chrismar, Julio. “Etnocacerismo y movimientos de pueblos originarios de Perú y Bolivia", Cuaderno de Difusión, Santiago:Academia de Guerra del Ejército, num. 27, 1-163, 2007.

Villagra, H. "Importancia estratégica de los ejes de integración regionales", Escenarios Actuales. CESIM, num. 13, 35-46, 2008.

Weldes, Jutta. “La construcción de los intereses nacionales” en: Andrés Santa Cruz (ed.), El constructivismo y las relaciones internacionales. México: CIDE, pp. 367- 418, 2009.

\section{Prensa:}

Diario Constitucional, (2019) “CGR determina que causal invocada por Ejército para celebrar trato directo no se encuentra justificada", martes 16 de abril (En línea): https:// www.diarioconstitucional.cl/noticias/asuntos-de-interes-

publico/2019/04/14/cgr-determina-que-causal-invocada-por-ejercito-para-celebrar-tratodirecto-no-se-encuentra-justificada/

La Estrella de Iquique, (2019) "Comunidades de Colchane piden reabrir el cruce ancestral entre Chile y Bolivia,", miércoles 17 de julio, página 3 (En línea) [Fecha consulta: 19.07.2019] http://www.estrellaiquique.cl/impresa/2019/07/17/full/cuerpo-principal/2/

La Tercera, (2019). "Piñera firma decreto que da atribuciones a las FFAA. Para combatir narcotráfico en las fronteras", martes 9 de julio (En línea) [Fecha consulta: 19.07.2019] https:// www.latercera.com/nacional/noticia/pinera-firma-decreto-darle-atribucioneslas-ff-aa-combatir-narcotrafico-fronteras/734127

La Tercera, (2018) “Extranjeros: 1.750 personas fueron expulsadas de Chile tras ser condenadas" sábado 2 de febrero (En línea) [Fecha consulta: 07.06.2019]

https:// www.latercera.com/nacional/noticia/extranjeros-1-750-personas-fueronexpulsadas-chile-tras-condenadas/512406/ 


\section{Fuentes primarias:}

Biblioteca del Congreso Nacional: “Autoriza ley de establecimiento y depósitos Francos. [Fecha consulta: 16.04.2019] En: https:/ / www.leychile.cl/Navegar?idNorma=6463 Comisión Seguridad Nacional y Geopolítica, Iquique, Chile. Mimeografiado, 53 págs.

Comisión Nacional de Reforma Regional y Administrativa (CONARA) "Chile, hacia un nuevo destino", 1976.

Gobierno Regional de Tarapacá (2014). Estrategia Regional de Desarrollo. (2014-2020) [Fecha consulta: 21.04.2019]

En: https://www.goretarapaca.gov.cl/wp-content/uploads/2016/02/estrategia.pdf

Gobierno Regional de Tarapacá (2019). Comunicado de prensa: "Habilitarán mecanismo para el tránsito vecinal en Colchane) [Fecha consulta: 19.07.2019] En: https:// www.goretarapaca.gov.cl/habilitaran-mecanismo-para-transito-vecinal-encolchane/ Intendencia Regional de Tarapacá, I Región. (1985) “Estrategia regional de desarrollo". Instituto Nacional de Derechos Humanos (2018). Informe Anual de Derechos Humanos. En: https://www.indh.cl/destacados-2/informe-anual-2018/

Instituto Nacional de Estadísticas. “Resultados Censo de población 2017" (15.08.2018) (en línea) [Fecha consulta: 03.01.2019] https://resultados.censo2017.cl/Region?R=R01

Ministerio de Economía, Fomento y Turismo (1985). “Decreto ley 600: estatuto de la inversión extranjera" [Fecha consulta: 03.01.2019]

En: https:// www.economia.gob.cl/1540/articles-185953_documento_1.pdf

Ministerio de Relaciones Exteriores. Dirección de Fronteras y Límites, Gobierno de Chile. ) [Fecha consulta: 02.05.2019] En: https://difrol.gob.cl/

Ministerio del Interior y Seguridad Pública, Gobierno de Chile. "Comunicado de la Subsecretaría del Ministerio del Interior y Seguridad Pública. Gobierno de Chile" (En línea) [Fecha de consulta 03.02.2019]_http://subinterior.gob.cl/noticias/2019/01/03/mas-de-2mil-extranjeros-fueron-expulsados-en

Ministerio de Desarrollo Social, Gobierno de Chile. “Documento sobre pueblos indígenas y Tribales, pp, 32 [Fecha consulta: 02.03.2019]

En: https://www.mop.cl/asuntosindigenas/Documents/convenio169.pdf

Oficina de Planificación Nacional, Santiago ODEPLAN, 1971.

Servicio Nacional de Geología y Mineria (SERNAGEOMIN). Anuario de la minería de Chile. Ministerio de Minería, Gobierno de Chile, 2017

Subsecretaría de Relaciones Exteriores (2019) “Acuerdo comerciales vigentes". [Fecha consulta: 03.04.2019] En: https://www.subrei.gob.cl/modulo-de-acuerdos-comerciales/ 